\title{
BMJ Open Sex-specific prevalence, inequality and associated predictors of hypertension, diabetes, and comorbidity among Bangladeshi adults: results from a nationwide cross-sectional demographic and health survey
}

\author{
Nausad Ali, ${ }^{1}$ Raisul Akram, ${ }^{2}$ Nurnabi Sheikh, ${ }^{3}$ Abdur Razzaque Sarker, ${ }^{\oplus}$ \\ Marufa Sultana ${ }^{\oplus, 5}$
}

To cite: Ali N, Akram R, Sheikh N, et al. Sex-specific prevalence, inequality and associated predictors of hypertension, diabetes, and comorbidity among Bangladeshi adults: results from a nationwide cross-sectional demographic and health survey. BMJ Open 2019;9:e029364. doi:10.1136/ bmjopen-2019-029364

- Prepublication history for this paper is available online. To view these files please visit the journal online (http://dx.doi. org/10.1136/bmjopen-2017016527).

Received 24 January 2019 Revised 09 August 2019 Accepted 19 August 2019
Check for updates

(C) Author(s) (or their employer(s)) 2019. Re-use permitted under CC BY-NC. No commercial re-use. See rights and permissions. Published by BMJ.

For numbered affiliations see end of article.

Correspondence to

Marufa Sultana;

marufa@icddrb.org

\section{ABSTRACT}

Objectives To determine the sex-specific prevalence, inequality and factors associated with healthcare utilisation for diabetes mellitus (DM), hypertension and comorbidity among the adult population of Bangladesh.

Study design This study analysed cross-sectional nationwide Bangladesh Demographic and Health Survey data from 2011. Comorbidity was defined as the coexistence of both DM and hypertension. Several socioeconomic and demographic factors such as age, sex, education, geographic location, administrative division, employment status, education and wealth index were considered as major explanatory variables. Inequality in prevalence and healthcare utilisation was measured using the 'Lorenz curve'. Adjusted multiple logistic regression models were performed to observe the effects of different factors and reported as adjusted ORs (AORs) with $95 \%$ Cls. A p value of $<0.05$ was adopted as the level of statistical significance.

Setting The study was conducted in Bangladesh. Participants A total of 7521 adult participants with availability of biomarkers information were included. Results The mean age of the study participants was 51.4 years $(\mathrm{SD} \pm 13.0)$. The prevalence of hypertension, diabetes and comorbidity were $29.7 \%, 11.0 \%$ and $4.5 \%$ respectively. Socioeconomic inequality was observed in the utilisation of healthcare services. A higher prevalence of hypertension and comorbidity was significantly associated with individuals aged $>70$ years (AOR 7.0, 95\% Cl 5.0 to 9.9; AOR 6.7, 95\% Cl 3.0 to 14.9 ). The risk of having hypertension, diabetes and comorbidity were significantly higher among more educated, unemployed as well as among individuals from Khulna division.

Conclusions The study revealed a rising prevalence of hypertension, diabetes and comorbidity with inequality in service utilisation. A joint effort involving public, private and non-governmental organisations is necessary to ensure improved accessibility in service utilisation and to reduce the disease burden.
Strengths and limitations of this study

- This paper determines sex-specific prevalence of most common non-communicable diseases (NCDs) including comorbidity using nationally representative survey data.

- The study identifies factors that significantly drive the prevalence of having NCDs including different sociodemographic and socioeconomic factors including rural-urban and administrative divisions for the whole country.

- The study also measures the inequality among socioeconomic groups and wealth quintiles in using available health services.

- While the large sample with biomarkers information allows us to draw the prevalence and determine associated factors, causal association could not be measured due to cross-sectional nature of the data.

- We were unable to draw associations with some other confounders such as family history, lifestyle, physical exercise, dietary practice, smoking behaviour and medication history due to the unavailability of data for those specific factors.

\section{BACKGROUND}

In recent years, the global burden of non-communicable diseases (NCDs) has rapidly emerged. ${ }^{12}$ In $2015,70 \%$ of all deaths worldwide were caused by NCDs, particularly cardiovascular diseases (CVDs) and diabetes mellitus (DM), while over $75 \%$ of deaths took place in low/middle-income countries (LMICs). ${ }^{3}$ The estimated global prevalence of DM among adults was approximately $8 \%$ in 2013, with nearly 382 million people living with diabetes, ${ }^{45}$ and over 3 million people die each year from diabetes and its related complications. ${ }^{6}$ A projected estimation revealed that the global prevalence of DM among all age 
groups will be approximately 592 million by $2035 .{ }^{5}$ Additionally, hypertension is another widely prevalent NCD and the strongest risk factor for CVD, ranking as the third highest cause of disability-adjusted life years (DALYs) ${ }^{7-9}$ Globally, hypertension is responsible for approximately 9.4 million annual deaths, with $80 \%$ of those deaths occurring in LMICs. ${ }^{11}$ The prevalence of hypertension is projected to increase from $26 \%$ in 2000 to $29 \%$ in 2025 , with LMICs such as Bangladesh suffering most. ${ }^{12}$

Over the last few decades, NCDs appeared as a crucial public health problem in Bangladesh. Various chronic conditions such as heart disease, stroke, cancer, chronic respiratory diseases and diabetes are increasing and contributed to approximately half $(54 \%)$ of the total annual deaths. ${ }^{13}$ Bangladesh is among the top 10 countries with the highest rates of projected age-standardised mortality among selected LMICs due to chronic diseases, particularly for CVDs and diabetes. ${ }^{14}$ In Bangladesh, about one-third of hospital admissions were due to major NCDs among individuals over 30 years of age ${ }^{15}$ and there is an increasing trend of demand for healthcare utilisation for diabetes and heart diseases. ${ }^{16}$ It is projected that the number of people with DM in Bangladesh will increase from 1.5 million in 2000 to 4 million in $2025 .{ }^{17}$ Moreover, DM itself is a risk factor for developing CVDs while the risk of developing CVDs also increases with the presence of hypertension. ${ }^{18}$ The coexistence of diabetes and hypertension accounts for greater risk of general disability and premature mortality. ${ }^{19}$ Although the disease pattern has been shifted from communicable diseases to NCDs, the health system of Bangladesh remains focused on addressing communicable diseases and maternal and child health needs. ${ }^{20}$ NCDs are associated with high out of pocket (OOP) expenditure in LMICs, ${ }^{21}$ and particular policy attention is required to mitigate NCD-related health and economic burdens. With the absence of social health protection, this issue is particularly crucial for Bangladesh, since $67 \%$ of total healthcare expenditure is borne by OOP payments. The latest estimation observed that approximately 0.7 million people fell into financial impoverishment due to high spending on NCDs in $2010 .^{22}$ In addition, an earlier study reported approximately US\$218 million of inpatient care spending for diabetic patients, which indicates substantial economic burden for the healthcare system of Bangladesh. ${ }^{23}$ As a result, these two NCDs (CVD and DM) contribute to an enormous economic burden for individuals, households and the national healthcare system especially for the low-income families and poor resource settings. ${ }^{19}$

Available reports and publications have largely examined and investigated hypertension and diabetes separately but provided little focus on sex-specific prevalence and factors associated with these NCDs. Since these two conditions (diabetes and hypertension) often coexist, it is also important to document the prevalence and associated comorbidity factors in the context of LMICs like Bangladesh so that policy-makers can adopt various needs and community-based prevention programme informed by the specific findings. Various factors such as rapid urbanisation, unhealthy diet, increased life expectancy, changing lifestyle, lack of physical exercise, lack of suitable places for walking or exercising, older age, high body mass index (BMI) and socioeconomic status of the people have led to an increase in the rate of NCDs in many LMICs such as Bangladesh. ${ }^{23-27}$ The present study had the scope to conduct these analyses using Bangladesh Demographic and Health Survey (BDHS) 2011 data since the data set included biomarker components to detect the risk of NCDs for the adult male and female population in Bangladesh. Furthermore, inequalities in prevalence and healthcare utilisation among socioeconomic groups for these conditions have not been reported in Bangladesh using nationwide survey data. As such, the objectives of this study were to determine the sex-specific prevalence of DM, hypertension and comorbidities, to assess the factors associated with these NCDs and to evaluate the inequalities of health service utilisation related to NCDs among the adult population in Bangladesh.

\section{METHODS}

\section{Study population and data source}

We used the nationally representative BDHS 2011 data set for this study. The survey was executed by the National Institute of Population Research and Training of the Ministry of Health and Family Welfare. ${ }^{28}$ This was the first national survey in Bangladesh that incorporated the measurement of biomarker information, including blood pressure and blood glucose levels. In the present study, eligible men and women aged 35 years or more were the study population.

\section{Sampling method and sample size}

The 2011 BDHS used a two-stage stratified cluster sampling frame to select households. The complete list of enumeration areas (EA) prepared by the Bangladesh Bureau of Statistics (BBS) was the sampling frame. ${ }^{29}$ The list of EAs covered the entire national population and 120 households from each EA were considered the primary sampling unit. In the first stage, a total of 600 EAs were selected, including urban and rural areas with the same proportional probability to EA size. In the second stage, 30 households were systematically sampled from each EA by considering reliable urban and rural demographics and health variables separately, for each of the seven administrative divisions, and for the country as a whole. ${ }^{28}$ As such, the survey selected 18000 residential households of which 17141 ever-married women were interviewed. To measure biomarker information, one-third of the 17 141 households were systematically selected (every third household). In this subsample, women and men aged 35 years and above were eligible to participate in a biomarker test that included the measurement of blood pressure, blood glucose and haemoglobin. The detailed sampling method, data collection processes, measurement procedures and questionnaires have been previously described 


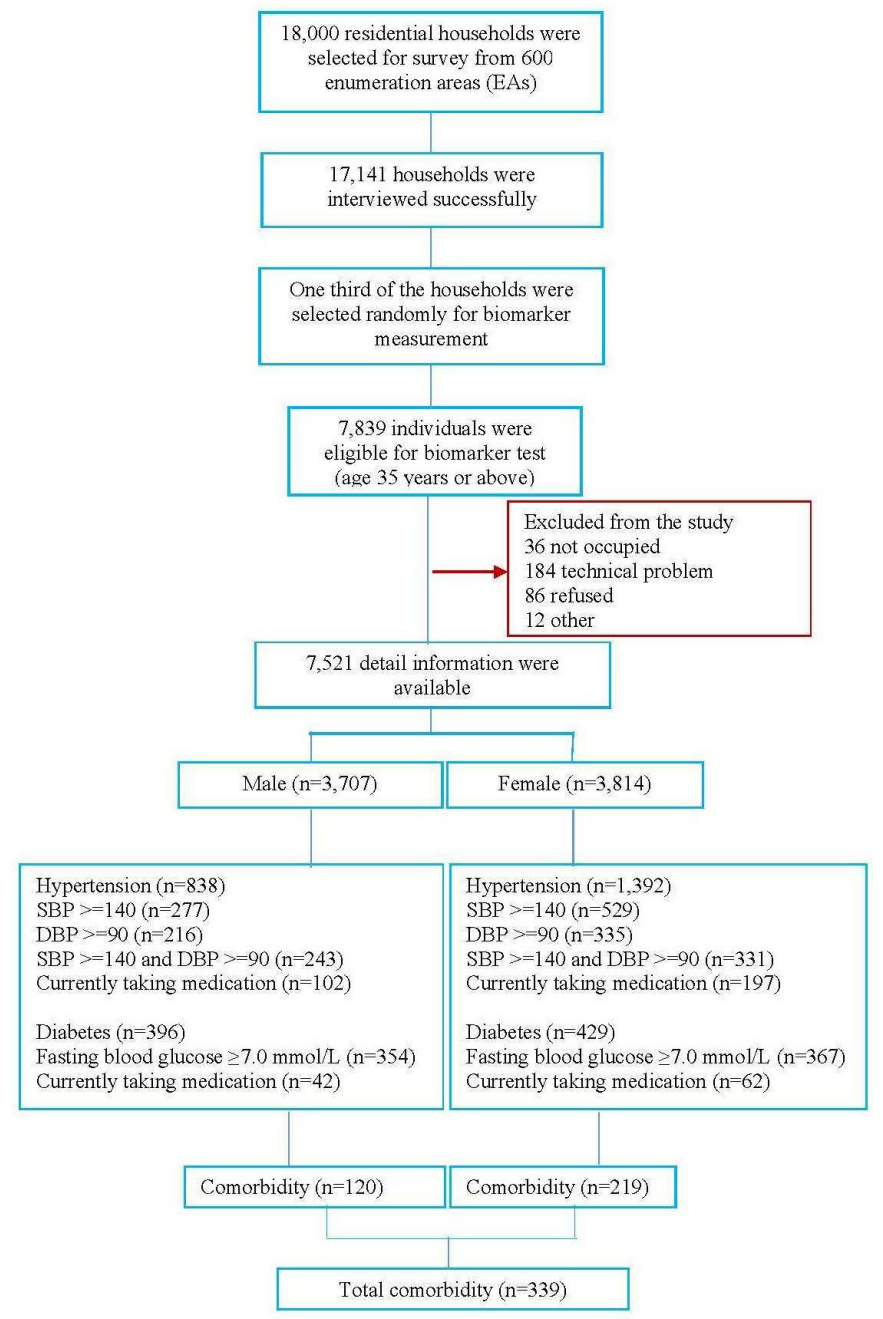

Figure 1 Study flow chart of the participants selection (aged 35 years or over) from Bangladesh Demographic and Health Survey 2011 survey data. DBP, diastolic blood pressure; SBP, systolic blood pressure.

elsewhere. ${ }^{28} \mathrm{~A}$ total of 7839 individuals aged 35 years and older were eligible for the biomarker test. However, 318 individuals were excluded due to missing information. Therefore, a final total of 7521 data were analysed, with 3707 men and 3814 women (figure 1).

\section{Measurement of biomarker component}

In this survey, hypertension was detected using the WHO recommended LIFE SOURCE UA-767 Plus Blood Pressure Monitor model. The device was automatic and included separate cuffs for small, medium and large arm circumferences to measure the blood pressure of respondents. With the assistance of health technicians, trained interviewers took three measurements of both systolic (SBP) and diastolic blood pressure (DBP) during the survey at approximately $10 \mathrm{~min}$ intervals between measurements. Haemoglobin, anthropometry and blood glucose testing were performed by the trained interviewers according to the recommended protocol. Before collecting a blood sample, the respondents were asked if they had eaten or drunk anything (except water) from the time they woke in the morning. If the subject was found to be fasting at the time of interview, a capillary blood sample was obtained from the middle or ring finger of the respondent. Blood glucose was measured using the HemoCue 201+blood glucose analyser. Consent was taken from each participant prior to conducting the tests. ${ }^{5}$

\section{Outcome variables}

The primary outcome variables were having 'hypertension', 'diabetes' and 'comorbidity'. The 2011 BDHS used the guideline of the American Heart Association (AHA) and WHO to determine the cut-off points for blood pressure and fasting plasma glucose measurements. ${ }^{28} \mathrm{An}$ individual was classified as hypertensive if SBP was $\geq 140 \mathrm{~mm}$ of mercury ( $\mathrm{mm} \mathrm{Hg}$ ) and/or DBP $\geq 90 \mathrm{~mm} \mathrm{Hg}$ and/or currently taking antihypertensive medication during the survey. ${ }^{30}$ An individual was considered to have a diabetes if fasting plasma glucose value was greater than or equal to $7.0 \mathrm{mmol} / \mathrm{L}$ or currently taking medication due to diabetes. ${ }^{31}$ Comorbidity was defined as the coexistence of hypertension and diabetes. ${ }^{32}$ BMI was defined as weight in kilograms divided by height in metres squared $(\mathrm{kg} /$ $\mathrm{m} 2$ ). According to the 2011 BDHS report, BMI less than 18.5 was used to define underweight or acute undernutrition, 25 to 30 indicated overweight status and 30 or above was defined as obesity for both men and women. ${ }^{28}$

\section{Major explanatory variables}

The major explanatory variables included in this study were based on the risk factors associated with hypertension and diabetes in earlier studies. ${ }^{12} 3334$ Participant age was categorised into seven groups (35-39, 40-44, 45-49, 50-54, 55-59, 60-64, 65-69 and 70 and above). Self-reported educational attainment of the study participant was used and categorised as 'no formal education', 'up to primary', 'secondary' and 'higher'. No formal education refers to 'not attaining any formal education', up to primary is defined as 'completing grade 5', secondary as 'completing grade 10' and higher was defined as 'attaining more than grade 10'. Moreover, the occupational status of the study participants was classified as 'unemployed' for not currently working, 'farmer' for land owners, poultry/cattle raising and home-based manufacturing, fishermen, 'self-employed' for rickshaw drivers, brick breakers, homemakers, carpenters, masons, any type of business, and 'others' included retired, housewives, religious leaders and beggars. Household socioeconomic status was measured by calculating wealth index using principal component analysis (PCA) to ascribe the ad hoc weights of the indicators. PCA is a combined measure of the cumulative living standard and is calculated by using selected household assets and generating a factor score as a weight. This technique includes calculating factor coefficient scores and standardising indicator variables. Indicator values were then multiplied by the factor loadings to generate the index value per household. ${ }^{35}$ Finally, the socioeconomic status of households having diabetes or/ and hypertension of household members was measured 
by calculating the wealth index as per the DHS guideline, resulting in categorisation into the 'poorest', 'poorer', 'middle', 'richer' and 'richest' quintiles.

\section{Measurement of inequality}

Inequality measurement was performed using the Lorenz curve. The Lorenz curve was initially developed by Max O. Lorenz to represent the inequality of wealth distribution. In this graphical representation, the $\mathrm{X}$-axis represents the proportion of the population ranked from the lowest to the highest wealth, while the Y-axis represents the cumulative distribution of total wealth. Consequently, it has been used in the public health context for risk prediction while health (the X-axis) represents the cumulative proportion of individuals in the population at risk, ranked accordingly from lowest to highest risk. In our study, inequality was measured based on socioeconomic status and wealth quintile using the Lorenz curve and represents the cumulative proportion of overall household wealth against the cumulative proportion of prevalence of hypertension, diabetes, comorbidity and healthcare utilisation (ie, the inequalities in prevalence or healthcare utilisation). Wealth index was calculated through PCA using BDHS survey data. ${ }^{28}$

This illustrates the concentration of risk in populations where 'concentration' denotes a deliberation of the highest risks of disease in the specific population. ${ }^{36}$ In this analysis, concentration was measured using the Gini coefficient, which is the ratio of the area between the perfect equality and perfect inequality lines. The $45^{\circ}$ line of the Lorenz curve indicates no disparity in the risk of disease and healthcare utilisation for DM, hypertension and comorbidity. ${ }^{37}$ Higher Gini coefficient values represent higher inequality among groups ${ }^{38}$ A Gini coefficient of zero (Gini $=0$ ) expresses perfect equality, while a Gini coefficient equal to one $(\mathrm{Gini}=1)$ denotes perfect inequality of prevalence and healthcare utilisation for the respective diseases. A Gini coefficient value of less than 0.20 represented low inequality, while values between 0.20 and 0.30 denoted moderate inequality, between 0.30 and 0.40 indicated high inequality, and a value of higher than 0.40 was considered extreme inequality for the prevalence and healthcare utilisation in this study. ${ }^{39-41}$

\section{Statistical analysis}

Data were analysed using STATA V.13.0 (Stata Corp LP) for descriptive analysis and multivariable logistic regression. Microsoft Excel V.13.0 was used to measure inequality by generating the Lorenz curve. Cross-tabulations (ie, bivariate) were performed to compare hypertension, diabetes and comorbidity status across covariate categories. A $\chi^{2}$ test was applied to assess the proportional differences in hypertension, diabetes and comorbidity across selected categorical variables (ie, age of the respondent, healthcare utilisation, education and wealth quintile). Both adjusted and unadjusted logistic regression models were used to examine the significant risk factors. At the first stage, we selected potential predictor variables, which were with a higher correlation with the dependent variable(s), and then performed bivariate logistic regression analysis (ie, the unadjusted regression model) to evaluate significant risk factors. To select the best performing statistically significant adjusted regression model, we performed stepwise multivariable logistic regression analysis by incorporating variables that were identified as statistically significant in bivariate analysis and to control confounding effects of all selected variables. Significant associations were determined at the 5\% alpha level $(\mathrm{p}<0.05)$. In the multivariable logistic regression models, we presented adjusted ORs (AORs) with 95\% CIs for multifactorial effects in the model. Since BDHS survey was based on the two-stage stratified cluster sampling technique, recommended sample weights provided by the 2011 BDHS were used for the analysis. ${ }^{28}$ The explanatory variables included age, sex (male/ female), place of residence (urban/rural), educational attainment, working status, mass media (access to a radio or television or not), currently used drug (s) (caffeine/ smoke), wealth index (poorest to richest), administrative divisions and BMI (normal, underweight, overweight or obese).

\section{Patient and public involvement}

No patient was involved in developing the research question, outcome measurement and design of the study. We are unable to disseminate the findings of the research directly to the study participants.

\section{RESULTS}

\section{Sociodemographic characteristics of the study participants}

The sociodemographic characteristics of the study participants are presented in table 1 . The mean age of the study participants was 51.4 years $(\mathrm{SD} \pm 13.0)$ while the highest percentage (19\%) belonged to 35-39-year-old age group. The male:female ratio was almost similar and $77 \%$ were from rural areas. The prevalence of hypertension, diabetes and comorbidity were $29.7 \%, 11.0 \%$ and $4.5 \%$, respectively, with a higher prevalence observed among women for all respective diseases. During illness, approximately $37 \%$ used healthcare due to hypertension compared with $34 \%$ for diabetes, with utilisation being higher among women. The majority of the participants had no formal education (63\%) and about half of them (52\%) were employed. Among all participants, $53 \%$ had accessibility to mass media. Regarding BMI, approximately $58 \%$ of the study population had a BMI within the normal range, while $31 \%$ were underweight and approximately $10 \%$ were overweight or obese. The prevalence of underweight status and obesity were higher for the female group (table 1).

\section{Prevalence of diabetes, hypertension and comorbidity}

The sex-specific prevalence of hypertension, diabetes and comorbidity are presented in table 2 and figure 2. Overall, the prevalence of hypertension was $22.6 \%$ and 
Table 1 Background characteristics of study participants aged 35 and over from Bangladesh Demographic and Health Survey 2011 survey data $(n=7521)$

\begin{tabular}{|c|c|c|c|}
\hline & Overall & Male & Female \\
\hline Characteristics & $\mathrm{N}(\%)$ & $\mathrm{N}(\%)$ & $\mathrm{N}(\%)$ \\
\hline \multicolumn{4}{|l|}{ Age (in years) } \\
\hline $35-39$ & $1402(18.6)$ & $617(16.7)$ & $785(20.6)$ \\
\hline $40-44$ & $1292(17.2)$ & $577(15.6)$ & $714(18.7)$ \\
\hline $45-49$ & $1199(16.0)$ & $595(16.1)$ & $604(15.8)$ \\
\hline $50-54$ & 1009 (13.4) & $590(15.9)$ & $419(11.0)$ \\
\hline $55-59$ & $666(8.9)$ & $297(8.0)$ & $370(09.7)$ \\
\hline $60-69$ & $1053(14.0)$ & $553(14.9)$ & $500(13.1)$ \\
\hline 70 and above & $900(12.0)$ & 478 (12.9) & $422(11.1)$ \\
\hline Mean age in years $($ mean $\pm S D)$ & $51.0(13.0)$ & $51.9(13.0)$ & $50.9(12.9)$ \\
\hline \multicolumn{4}{|l|}{ Place of residence } \\
\hline Urban & $1754(23.3)$ & $882(23.8)$ & $872(22.9)$ \\
\hline Rural & $5767(76.7)$ & 2825 (76.2) & $2942(77.1)$ \\
\hline \multicolumn{4}{|l|}{ Hypertension* } \\
\hline Yes & $2230(29.7)$ & $838(22.6)$ & $1392(36.5)$ \\
\hline No & $5291(70.3)$ & $2869(77.4)$ & $2422(63.5)$ \\
\hline \multicolumn{4}{|l|}{ Diabetes† } \\
\hline Yes & $825(11.0)$ & $396(10.7)$ & $429(11.2)$ \\
\hline No & $6696(89.0)$ & 3311 (89.3) & $3385(88.8)$ \\
\hline \multicolumn{4}{|l|}{ Comorbidity } \\
\hline Yes & $339(4.5)$ & $120(3.2)$ & $219(5.7)$ \\
\hline No & $7182(95.5)$ & $3587(96.8)$ & $3595(94.3)$ \\
\hline \multicolumn{4}{|l|}{$\begin{array}{l}\text { Healthcare utilisation } \\
\text { (\% of exposure) }\end{array}$} \\
\hline Hypertension & $814(36.5)$ & $269(32.1)$ & $545(39.1)$ \\
\hline Diabetes & $283(34.3)$ & $127(32.0)$ & $156(36.4)$ \\
\hline Comorbidity & $107(31.7)$ & 38 (31.5) & $70(31.8)$ \\
\hline \multicolumn{4}{|l|}{ Education } \\
\hline No formal education & $4744(63.1)$ & $1397(37.7)$ & $3346(87.7)$ \\
\hline Up to primary & $1390(18.5)$ & 1045 (28.2) & $345(9.0)$ \\
\hline Secondary & $929(12.4)$ & $828(22.3)$ & $101(2.6)$ \\
\hline Higher & $458(6.1)$ & $437(11.8)$ & $22(0.6)$ \\
\hline \multicolumn{4}{|l|}{ Working status } \\
\hline Unemployed & $4263(56.7)$ & $539(14.6)$ & $3723(97.6)$ \\
\hline Farmer & $1457(19.4)$ & $1444(39)$ & $13(0.3)$ \\
\hline Self-employed & $1004(13.4)$ & $945(25.5)$ & $59(1.6)$ \\
\hline Business & $734(9.8)$ & 725 (19.6) & $9(0.2)$ \\
\hline Others & $63(0.8)$ & $53(1.4)$ & $10(0.3)$ \\
\hline \multicolumn{4}{|l|}{ Mass media } \\
\hline Not exposed & 3954 (52.6) & $1960(52.9)$ & $1994(52.3)$ \\
\hline Exposed & $3567(47.4)$ & $1747(47.1)$ & $1820(47.7)$ \\
\hline \multicolumn{4}{|l|}{ Current drug use (7515) } \\
\hline Exposed & $1975(26.3)$ & $975(26.3)$ & $1000(26.3)$ \\
\hline Not exposed & $5540(73.7)$ & $2732(73.7)$ & $2808(73.7)$ \\
\hline
\end{tabular}


Table 1 Continued

\begin{tabular}{lccc}
\hline & Overall & Male & Female \\
\cline { 2 - 2 } Characteristics & $\mathbf{N}(\%)$ & $\mathbf{N}(\%)$ & \\
\hline Wealth index & & & \\
\hline Poorest & $1469(19.5)$ & $739(20.0)$ & $729(19.1)$ \\
\hline Poorer & $1431(19.0)$ & $718(19.4)$ & $714(18.7)$ \\
\hline Middle & $1488(19.8)$ & $719(19.4)$ & $769(20.2)$ \\
\hline Richer & $1560(20.7)$ & $759(20.5)$ & $800(21.0)$ \\
\hline Richest & $1573(20.9)$ & $772(20.8)$ & $801(21.0)$ \\
\hline Administrative division & & & \\
\hline Barisal & $425(5.7)$ & $206(5.5)$ & $220(5.8)$ \\
\hline Chittagong & $1251(16.6)$ & $576(15.5)$ & $675(17.7)$ \\
\hline Dhaka & $2451(32.6)$ & $1208(32.6)$ & $1243(32.6)$ \\
\hline Khulna & $991(13.2)$ & $499(13.5)$ & $492(12.9)$ \\
\hline Rajshahi & $1079(14.4)$ & $540(14.6)$ & $539(14.1)$ \\
\hline Rangpur & $899(12.0)$ & $473(12.8)$ & $425(11.1)$ \\
\hline Sylhet & $425(5.7)$ & $204(5.5)$ & $221(5.8)$ \\
\hline Body mass index $(n=5213)$ & & & \\
\hline Normal (18.50-25) & $3037(58.3)$ & $2229(61.8)$ & $808(50.4)$ \\
\hline Underweight $(<18.50)$ & $1634(31.3)$ & $1051(29.1)$ & $582(36.3)$ \\
\hline Overweight or obese $(>25)$ & $542(10.4)$ & $328(9.1)$ & $214(13.3)$ \\
\hline
\end{tabular}

*An individual is classified as having hypertension if $\mathrm{s} / \mathrm{he}$ has blood pressure levels $>=140 \mathrm{~mm} \mathrm{Hg} \mathrm{SBP}$ or $>=90 \mathrm{~mm} \mathrm{Hg} \mathrm{DBP}$, or $\mathrm{s} / \mathrm{he}$ is currently taking antihypertensive medication to lower their blood pressure.

$\dagger$ An individual is classified as having diabetes if $\mathrm{s} / \mathrm{he}$ reports taking medication for diabetes or has fasting blood glucose $\geq 7.0 \mathrm{mmol} / \mathrm{L}$. $\ddagger$ Comorbidity is defined as the presence of both hypertension and DM.

$36.5 \%$ for men and women, respectively. The prevalence of hypertension was highest among those of $70+$ years of age $(\mathrm{p}<0.001)$ compared with the other age categories for both men and women. Hypertension was highly prevalent among urban residents (men vs women: 28.2 vs $43.7 ; \mathrm{p}<0.001$ ) and higher educated individuals (men vs women: 34.8 vs $89.3 ; \mathrm{p}<0.001)$. All respective diseases were highly prevalent among richest wealth quintiles compared with the poorest, and women suffered significantly more than men (table 2 and figure 3 ). We also observed that overweight or obese individuals were more likely to have hypertension compared with others who had normal BMI.

The overall prevalence of diabetes was $10.7 \%$ and $11.2 \%$ for men and women, respectively. A higher percentage diabetes prevalence was observed among 55-59-year-old individuals (men vs women: 19.3 vs 15.3 ; $\mathrm{p}<0.001$ ) (figure 2). The prevalence of diabetes among urban residents (men vs women: 15.0 vs $17.2 ; \mathrm{p}<0.001$ ) was twofold compared with rural areas. The prevalence of diabetes was significantly higher $(45.1 \%)$ among higher educated females than their male counterparts (21.4). In addition, diabetes prevalence was significantly higher among individuals who belonged to the richest households $(\mathrm{p}<0.001)$. Considering administrative divisions, Chittagong has had the highest prevalence of diabetes
(14\%) for either sex. Similar to hypertension, diabetes prevalence was also higher among overweight or obese individuals irrespective of sex.

In this study, the coexistence of diabetes and hypertension was $3.2 \%$ and $5.7 \%$ for men and women, respectively (figure 2). Notably, a higher percentage of comorbidity was observed among 55-59-year-old aged individuals. The urban residents (men vs women: $5.9 \%$ vs $10.3 \%$; $\mathrm{p}<0.001$ ), higher educated individuals (men vs women: $8.6 \%$ vs $43.1 \%$; $\mathrm{p}<0.001$ ), those with mass media exposure (men vs women: $4.9 \%$ vs $8.2 \%$; $p<0.001)$, members of wealthiest households (men vs women: $8.5 \%$ vs $12.7 \%$; $\mathrm{p}<0.001$ ) and those who lived in Chittagong division (men vs women: $6.3 \%$ vs $7.2 \%$; $\mathrm{p}<0.001)$ exhibited a significantly higher prevalence of comorbidity (table 2 ).

\section{Inequality in the prevalence of DM, hypertension and comorbidity as well as healthcare utilisation}

Figure 3 presents the inequality of the prevalence and healthcare service utilisation for DM, hypertension and comorbidity using concentration curves and the Gini coefficient. The Gini coefficient values were $0.13,-0.003$ and 0.272 for hypertension, diabetes and comorbidity, respectively, which indicated that very low levels of inequality existed for the prevalence of hypertension and DM (Gini coefficient $<0.20$ ), while moderate inequality existed for 


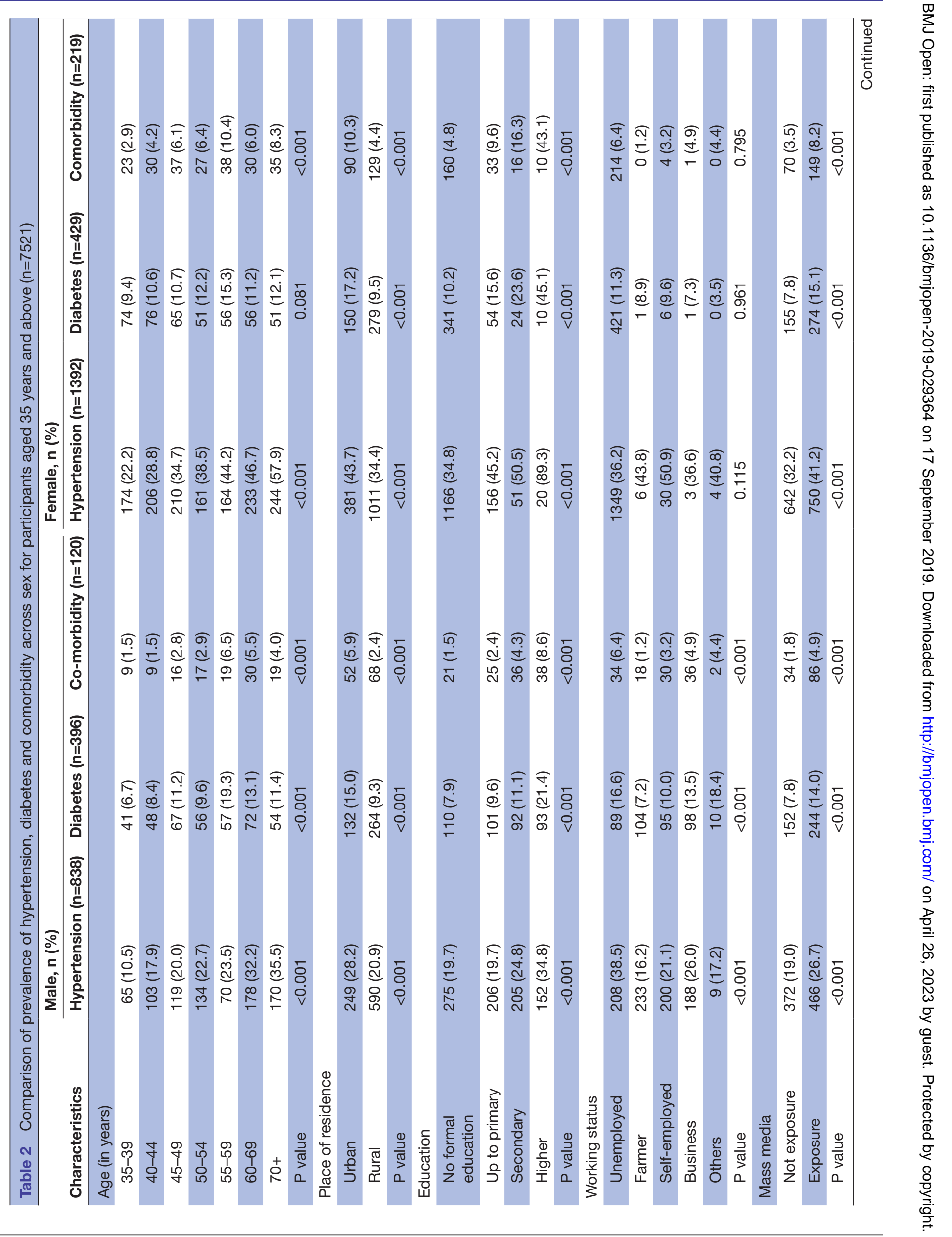




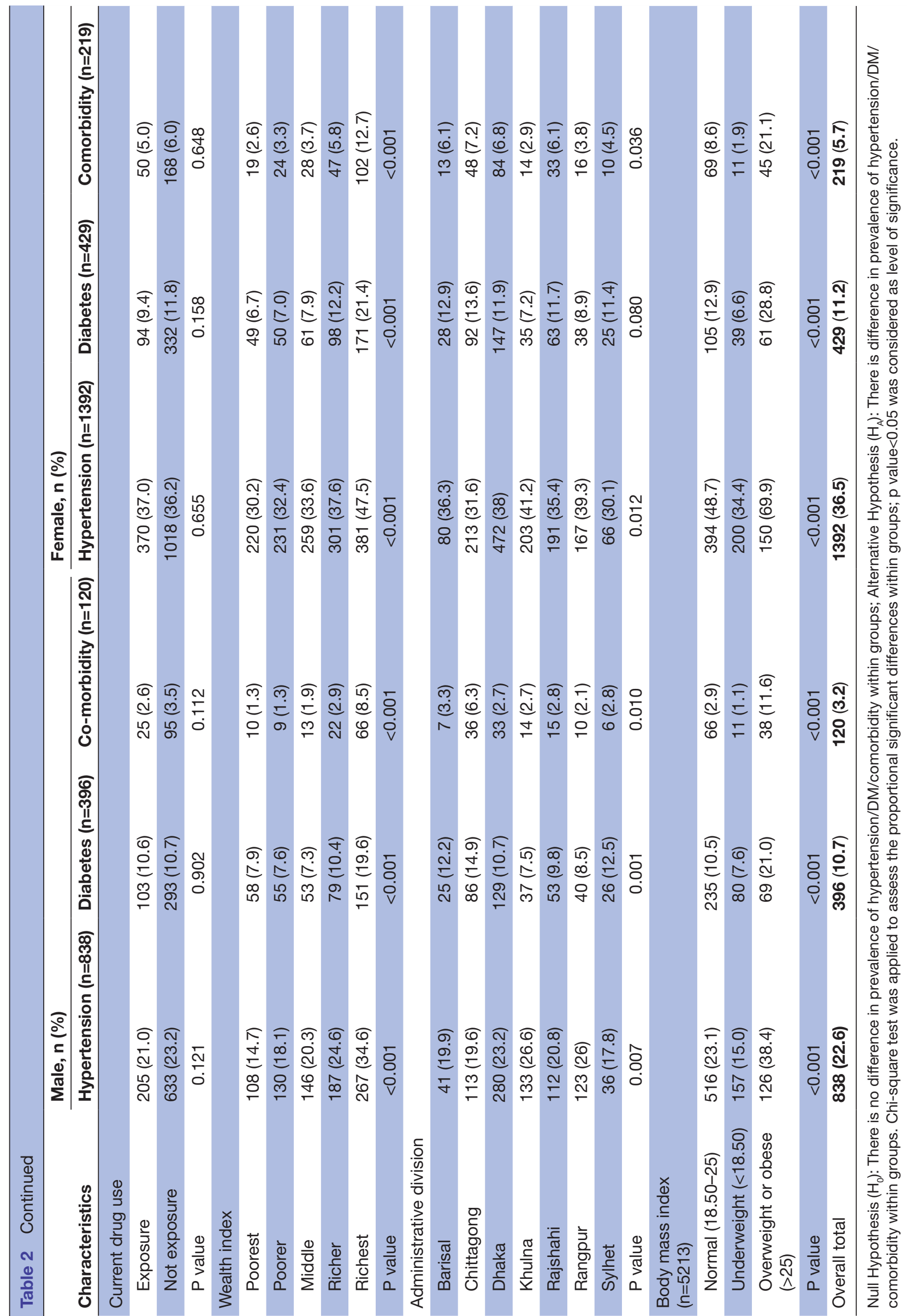




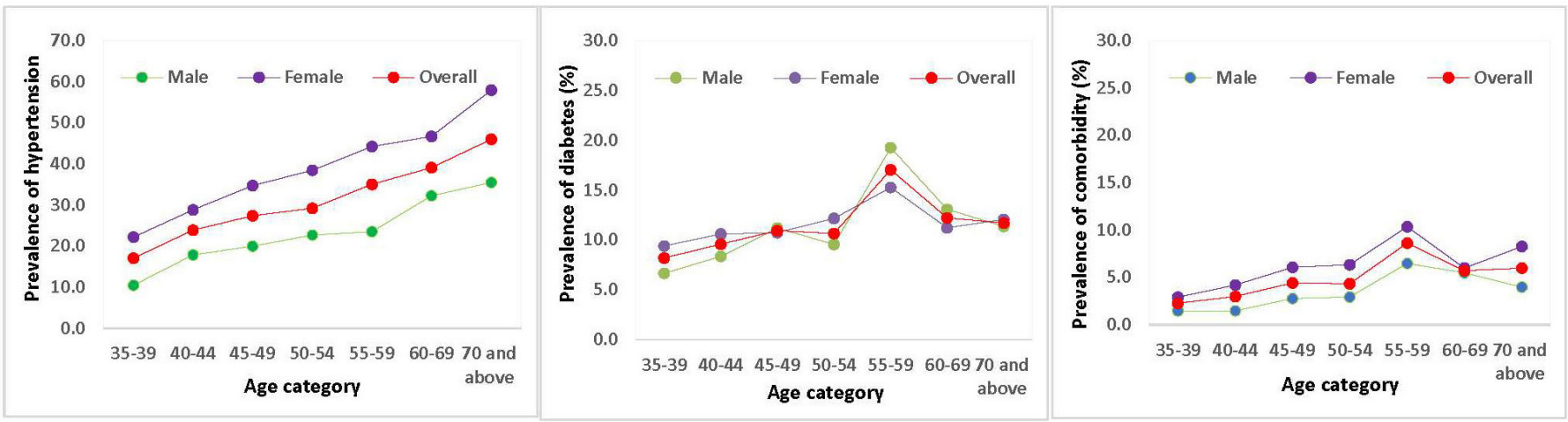

Figure 2 Prevalence of hypertension, diabetes and co-morbidity across sex for participants aged 35 years and above $(n=7521)$.

comorbidity (Gini coefficient $<0.30$ ) among different socioeconomic groups. However, for healthcare utilisation, higher socioeconomic inequality (Gini coefficient $>0.40$ ) was observed for DM and comorbidity (figure 1).

\section{Factors associated with hypertension, diabetes and comorbidity}

Table 3 shows the risk factors associated with the NCDs in three individual multiple logistic regression models based on the socioeconomic and demographic characteristics of participants. We observed a positive relationship between increased age and NCDs. The risk of hypertension was 7.0 (CI 5.0 to $9.9 ; \mathrm{p}<0.001$ ) and diabetes (CI 2.0 to $4.6 ; \mathrm{p}<0.001$ ) was 3.1 times more likely among individuals aged $70+$ and $55-59$ years than the reference group ( $<40$ years). The risk for comorbidity was 6.7 (CI 3.0 to $14.9 ; \mathrm{p}<0.001)$ times higher among $70+$ years age group followed by individuals aged 55 to 59 years (AOR 6.0 ; CI 2.8 to $13.0 ; \mathrm{p}<0.001)$. Women were significantly more likely to have hypertension (AOR 2.0; CI 1.6 to 2.5; $\mathrm{p}<0.001$ ) and comorbidity (AOR 1.8; CI 1.2 to 2.8; $\mathrm{p}<0.01)$ compared with men. The risk for hypertension (AOR 1.5; CI 1.1 to 2.0; $\mathrm{p}<0.001$ ), diabetes (AOR 2.1; CI 1.5 to $2.9 ; \mathrm{p}<0.001$ ) and comorbidity (AOR 3.0; CI 1.8 to $5.1 ; \mathrm{p}<0.001$ ) was significantly higher for higher educated individuals. The risk of hypertension and diabetes was significantly higher among individuals who were not

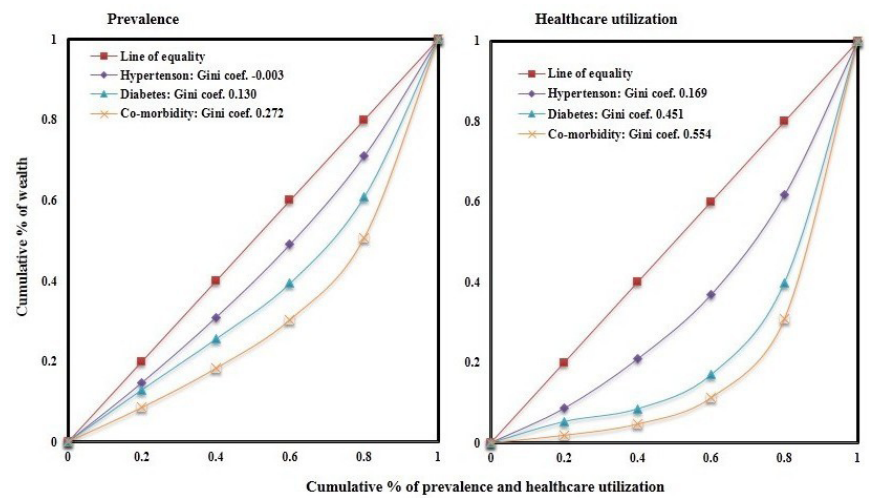

Figure 3 Concentration curves for prevalence and healthcare utilisation of hypertension, diabetes and comorbidity. employed (table 3). The likelihood of hypertension was 2.2 (CI 1.6 to $2.9 ; \mathrm{p}<0.001$ ) times higher among individuals belonging to highest wealth quintiles compared with the poorest. Among the divisions, the risk of having hypertension was significantly higher among individuals who lived in Khulna (AOR 1.7; $<<0.001$ ), Rajshahi (AOR 1.4; $\mathrm{p}<0.05$ ) and Rangpur (AOR 1.9; $\mathrm{p}<0.001$ ) divisions. We observed a significant positive association between BMI and NCDs. Furthermore, the obese or overweight individuals were 2.0 times (CI 1.57 to $2.51 ; \mathrm{p}<0.001$ ) more likely to develop hypertension. A similar pattern was also observed for diabetes and comorbidity (table 3).

\section{DISCUSSION}

NCDs are becoming one of the major health challenges in Bangladesh. The latest report published by the WHO indicated that nearly all Bangladeshi adults are affected by at least one NCD risk factor (eg, smoking, alcohol intake, low physical activity, obesity, hypertension and DM) while a large proportion is affected by at least two hypertension and DM risk factors. ${ }^{42}$ This leads to a double burden for the population of Bangladesh because of its existing burden of infectious diseases alongside the rising prevalence of NCDs. Additionally, the real health burden of NCDs remains unknown, since $83 \%$ of Bangladeshi adults have never had a blood glucose measurement and only $3.9 \%$ respondents reported that they were diagnosed with DM while approximately 33\% have never had a blood pressure measurement (reported prevalence of 12\%). ${ }^{42}$ Thus, most NCDs such as hypertension and DM remain undiagnosed and untreated. This study attempted to mitigate this gap by investigating the prevalence and risk factors using survey data including biomarker tests to determine prevalence associated with hypertension, diabetes and comorbidity which is nationally representative. The difference in prevalence between earlier reports and the current study findings can be explained by the use of biomarkers examining the actual prevalence rather than assessing history of participants.

Our study observed that the prevalence of hypertension is higher than DM, while female have a higher prevalence than their male counterparts for both hypertension and 
Table 3 Multivariate logistic regression model to determine factors associated with hypertension, diabetes and comorbidity among participants aged 35 years and above

\begin{tabular}{|c|c|c|c|}
\hline \multirow[b]{3}{*}{ Characteristic } & Model I & Model II & Model III \\
\hline & Hypertension & Diabetes & Comorbidity \\
\hline & AOR (95\% Cl) & AOR (95\% Cl) & AOR $(95 \% \mathrm{Cl})$ \\
\hline \multicolumn{4}{|l|}{ Age (in years) } \\
\hline $35-39$ (ref) & 1.00 & 1.00 & 1.00 \\
\hline $40-44$ & $1.9^{* \star \star}(1.4$ to 2.7$)$ & $1.3(0.9$ to 2.1$)$ & 1.1 (0.4 to 2.9$)$ \\
\hline $45-49$ & $2.3^{\star \star \star}(1.6$ to 3.2$)$ & $1.9^{\star \star \star}(1.3$ to 3.0$)$ & 2 (0.9 to 4.8$)$ \\
\hline $50-54$ & $2.9^{\star \star \star}(2.1$ to 4.0$)$ & $1.9^{\star \star \star}(1.3$ to 2.9$)$ & $3.1^{\star \star}$ (1.4 to 6.6$)$ \\
\hline $55-59$ & $3.3^{\star \star \star}(2.3$ to 4.6$)$ & $3.1^{\star \star \star}(2.0$ to 4.6$)$ & $6.0^{\star \star \star}(2.8$ to 13.0$)$ \\
\hline $60-69$ & $4.7^{\star \star \star}(3.4$ to 6.4$)$ & $2.3^{\star \star \star}(1.5$ to 3.5$)$ & $5.0^{\star \star \star}(2.3$ to 10.7$)$ \\
\hline $70+$ & $7.0^{\star \star \star}(5.0$ to 9.9$)$ & $2.2^{\star \star \star}(1.4$ to 3.5$)$ & $6.7^{\star \star \star}(3.0$ to 14.9$)$ \\
\hline \multicolumn{4}{|l|}{ Sex } \\
\hline Male (ref) & 1.00 & 1.00 & 1.00 \\
\hline Female & $2.0^{\star \star \star}(1.6$ to 2.5$)$ & 0.8 (0.6 to 1.1$)$ & $1.8^{\star \star}(1.2$ to 2.8$)$ \\
\hline \multicolumn{4}{|l|}{ Palace of residence } \\
\hline Urban (ref) & $1(0.9$ to 1.2$)$ & $1.1(0.8$ to 1.3$)$ & $1.2(0.8$ to 1.6$)$ \\
\hline Rural & 1.00 & 1.00 & 1.00 \\
\hline \multicolumn{4}{|l|}{ Education } \\
\hline No formal education (ref) & 1.00 & 1.00 & 1.00 \\
\hline Up to primary & $0.9(0.7$ to 1$)$ & $1.2(1.0$ to 1.6$)$ & $1.29(0.9$ to 1.9$)$ \\
\hline Secondary & 1.1 (0.9 to 1.3$)$ & $1.2(0.9$ to 1.6$)$ & $1.8^{\star \star}(1.2$ to 2.8$)$ \\
\hline Higher & $1.5^{\star \star \star}(1.1$ to 2.0$)$ & $2.1^{\star \star \star}(1.5$ to 2.9$)$ & $3.0^{\star \star \star}(1.8$ to 5.1$)$ \\
\hline \multicolumn{4}{|l|}{ Working status } \\
\hline Unemployed (ref) & 1.00 & 1.00 & 1.00 \\
\hline Farmer & $0.6^{\star \star \star}(0.5$ to 0.8$)$ & $0.6^{\star \star}(0.5$ to 0.9$)$ & $0.5^{\star}(0.3$ to 1$)$ \\
\hline Self-employed & 0.8 (0.6 to 1.1$)$ & $0.5^{\star \star \star}(0.4$ to 0.8$)$ & 0.6 (0.4 to 1.1$)$ \\
\hline Business & 1.0 (0.7 to 1.3$)$ & 0.8 (0.5 to 1.1$)$ & 1.1 (0.6 to 1.8$)$ \\
\hline Others & $0.5^{\star}(0.3$ to 1.0$)$ & $1.2(0.6$ to 2.5$)$ & $0.9(0.2$ to 3.6$)$ \\
\hline \multicolumn{4}{|l|}{ Mass media } \\
\hline Not exposure & 1.2 (1.0 to 1.4$)$ & 0.8 (0.6 to 1.1$)$ & 0.9 (0.6 to 1.4$)$ \\
\hline Exposure (ref) & 1.00 & 1.00 & 1.00 \\
\hline \multicolumn{4}{|l|}{ Wealth index } \\
\hline Poorest (ref) & 1.00 & 1.00 & 1.00 \\
\hline Poorer & 1.1 (0.9 to 1.3 ) & 0.9 (0.6 to 1.2$)$ & 0.8 (0.4 to 1.4$)$ \\
\hline Middle & 1.2 (1.0 to 1.6$)$ & $0.7^{\star}(0.5$ to 0.9$)$ & 0.7 (0.4 to 1.3$)$ \\
\hline Richer & $1.5^{\star \star \star}(1.2$ to 1.9$)$ & 0.9 (0.6 to 1.3$)$ & 0.9 (0.5 to 1.7$)$ \\
\hline Richest & $2.2^{* \star \star}(1.6$ to 2.9$)$ & 1.5 (1.0 to 2.2$)$ & $1.9(1.0$ to 3.7$)$ \\
\hline \multicolumn{4}{|l|}{ Administrative division } \\
\hline Barisal & 1.3 (0.9 to 1.9$)$ & $1(0.6$ to 1.7$)$ & 1.4 (0.6 to 3.3$)$ \\
\hline Chittagong & $1(0.7$ to 1.3$)$ & 1.1 (0.7 to 1.6$)$ & 1.7 (0.9 to 3.4$)$ \\
\hline Dhaka & $1.3(0.9$ to 1.7$)$ & $0.8(0.5$ to 1.1$)$ & $1.1(0.5$ to 2.1$)$ \\
\hline Khulna & $1.7^{\star \star \star}(1.2$ to 2.4$)$ & $0.4^{\star \star \star}(0.3$ to 0.7$)$ & 0.7 (0.3 to 1.5$)$ \\
\hline Rajshahi & $1.4^{\star}$ (1.0 to 2$)$ & 0.9 (0.6 to 1.4$)$ & 1.4 (0.7 to 2.9$)$ \\
\hline Rangpur & $1.9^{* \star \star}(1.4$ to 2.7$)$ & 0.7 (0.5 to 1.1$)$ & $1.0(0.5$ to 2.2$)$ \\
\hline Sylhet (ref) & 1.00 & 1.00 & 1.00 \\
\hline
\end{tabular}


Table 3 Continued

\begin{tabular}{|c|c|c|c|}
\hline & Model I & Model II & Model III \\
\hline & Hypertension & Diabetes & Comorbidity \\
\hline Characteristic & AOR (95\% Cl) & AOR (95\% Cl) & AOR (95\% Cl) \\
\hline \multicolumn{4}{|l|}{ Body mass index } \\
\hline Normal (18.50-25) (ref) & 1.00 & 1.00 & 1.00 \\
\hline Underweight (<18.50) & $0.5^{\star \star \star}(0.5$ to 0.6$)$ & $0.7^{* \star \star}(0.5$ to 0.9$)$ & $0.3^{\star \star \star}(0.2$ to 0.5$)$ \\
\hline Overweight or obese (>25) & $2.0^{\star \star \star}(1.6$ to 2.4$)$ & $1.8^{\star \star \star}(1.4$ to 2.4$)$ & $2.4^{\star \star \star}(1.7$ to 3.3$)$ \\
\hline Constant & $0.064^{\star \star \star}(0.04$ to 0.11$)$ & $0.105^{\star \star \star}(0.05$ to 0.20$)$ & $0.007^{\star \star \star}(0.00$ to 0.02$)$ \\
\hline $\mathrm{N}$ & 7521 & 7521 & 7521 \\
\hline $\operatorname{LR} \chi^{2}(29)$ & 835.52 & 291.99 & 349.26 \\
\hline Log likelihood & -2748.39 & -1691.7765 & -800.7656 \\
\hline Prob $>\chi^{2}$ & $<0.001$ & $<0.001$ & $<0.001$ \\
\hline Mean VIF & 2.42 & 2.42 & 2.44 \\
\hline Pseudo $R^{2}$ & 0.13 & 0.08 & 0.18 \\
\hline
\end{tabular}

${ }^{*} \mathrm{P}<0.05,{ }^{* *} \mathrm{p}<0.01,{ }^{* * *} \mathrm{p}<0.001$.

AOR, adjusted OR; VIF, variance inflation factors.

diabetes. Notably, older age, sex, educational attainment, occupational status, wealth status, BMI and geographic location were significantly associated with NCDs in the present study which is consistent with the findings of other developing countries. ${ }^{43-50}$ Like earlier studies, we also found that the risk factors of having comorbidity were significantly associated with older age, sex, higher educational level, regional variation, higher BMI (eg, overweight, obese) and the working status of individuals. ${ }^{32} 5152$ This may be a result of older people often suffering from various health issues such as reduced physical activities, poor nutritional status and poor immunity. ${ }^{53}$ Furthermore, we observed that women were more likely to have hypertension and comorbidity. This higher prevalence among women can be explained by various biological and environmental factors. ${ }^{54}$ In addition, a number of studies observed that mental stress is often associated with high blood pressure, and middle-aged women may be more exposed to stress particularly during menopause. ${ }^{556}$ Moreover, BMI scores were found higher among women than men, which is in line with our study. ${ }^{57}$ However, this is not always observed in other settings. For example, a study conducted in India indicated that men had a higher likelihood of having hypertension. ${ }^{58}$ Additionally, a review study including sub-Saharan African regions found that the prevalence of diabetes is higher among men. ${ }^{59}$

Regarding the level of education, the present study observed that NCDs are more common among individuals that are more educated. Likewise, a study in Nepal documented that the coexistence of diabetes and hypertension was approximately eight times higher among more educated individuals. ${ }^{18}$ This might be explained by the fact that higher educated people often have better opportunities to make their life more comfortable with better a working environment, in addition to higher income and expenditure (eg, food, transport) which limits their physical activity and thus increases the risk of developing NCDs. ${ }^{60}{ }^{61}$ However, such findings were not always observed. ${ }^{19}$ Many studies observed that moderate or high levels of physical activities were negatively associated with hypertension and diabetes. ${ }^{62}{ }^{63}$ The present study found similar findings, as people who were involved in any type of work were at lower risk for diabetes and hypertension. According to the report of the American Diabetes Association (ADA), physical activity increases oxygen consumption throughout the body and maintains blood glucose levels to preserve the central nervous system. ${ }^{64}$ Congruent with earlier studies, we observed that wealth status and NCDs were positively associated, while individuals from the highest wealth quintile were more prone to developing hypertension than those of the lowest wealth quintile. ${ }^{65}$ The reasons behind this trend might include less physical labour, sedentary lifestyles, being overweight or obese and stress, all of which increase the risk of developing hypertension. The risk of having diabetes as well as comorbidity was higher among the wealthiest households compared with the poorest and indicated borderline significance among them. Another study determined that the risk of having diabetes and the coexistence of diabetes and hypertension were 1.8 times and 2.2 times more likely, respectively, among individuals from the richest quintile where the level of significance was almost similar to what we observed in the present study. ${ }^{65}$

In the current study, the highest risk of hypertension was observed in the northwestern and southern portions (Rangpur, Rajshahi and Khulna divisions) of the country, whereas the southern (Khulna division) portion of the country had a lower risk of diabetes and Chittagong 
division had a significantly higher risk of comorbidity. Notably, the similar risk factors were found for hypertension $^{12}{ }^{12}$ and diabetes ${ }^{66}$ among earlier studies conducted in Bangladesh. This geographical variation for hypertension can be explained by a higher intake of raw salt in the coastal areas, variation in dietary habits and lower awareness regarding hypertension.$^{67}$ The lower risk for diabetes in Khulna division could be due to greater accessibility to healthcare services, sociodemographic conditions as well as awareness, all of which contribute to control DM. ${ }^{68}$ However, the reasons for the significantly higher risk of comorbidity in the Chittagong division remains unknown and needs to be investigated in different demographic regions of Bangladesh. Both overweight and obese conditions were significantly associated with the prevalence of hypertension, diabetes and comorbidity as potential risk factors. ${ }^{69}$ The reasons behind these factors might be explained by the fact that excess body fat leads to increased insulin resistance ${ }^{70}$ thereby acting as a predisposing factor for developing NCDs. ${ }^{70} 71$ Similar to our findings, overweight or obese condition were also noted as identified risk factors in other investigations. ${ }^{72} 73$

The existence of socioeconomic inequalities was observed in our study. The inequalities of healthcare services among the richest to poorest might be due to high treatment cost, lack of financial resources, affordability and the absence of financial health protection schemes in Bangladesh as well as the insensibility of appropriate healthcare, which results in a higher probability of experiencing catastrophic health expenditure and impoverishment particularly for the poorest households. ${ }^{74}$ The results of this study were also consistent with other studies that revealed NCDs in lower socioeconomic conditions increasing the risk of households facing catastrophic health expenditure and impoverishment, which negatively influenced the rate of healthcare utilisation. ${ }^{75-77}$

\section{Strengths and limitations}

The study has several limitations. First, this study was based on cross-sectional data that failed to establish a causal relationship. Second, due to the unavailability of data on potential confounders for developing diabetes such as family history of DM and hypertension, lifestyle, physical exercise, dietary practice, smoking behaviour and medication history, these variables were not included in this analysis. Despite these limitations, the main strength of this study includes national representation of sex-specific prevalence, associated factors and socioeconomic inequalities related to NCDs in Bangladesh spanning both urban and rural areas and conducted using robust methodologies.

\section{CONCLUSIONS}

Our study findings revealed that the prevalence of hypertension, diabetes and comorbidity were comparatively higher among women, urban residents, higher educated individuals and individuals from wealthier quintiles.
Elderly people also had a higher risk of developing hypertension. Therefore, various community-based health promotion interventions should target the older population to tackle the burden of NCDs. The findings of the present study suggest that policy-makers should give high priorities for tackling NCDs by reforming healthcare systems to ensure the accessibility as well as the affordability of treatment while considering low-income groups to ensure equity in defeating illnesses and reducing financial burden. A joint effort involving public, private and non-governmental organisations is necessary to ensure better accessibility and to reduce the mortality and morbidity burden due to NCDs.

\section{Author affiliations}

${ }^{1}$ Health Systems and Population Studies Division, International Centre for Diarrhoeal Disease Research, Bangladesh (icddr,b), Dhaka, Bangladesh

${ }^{2}$ Bangladesh Institute of Development Studies, Dhaka, Bangladesh

${ }^{3}$ Institute of Health Economics, University of Dhaka, Dhaka, Bangladesh

${ }^{4}$ Nutrition and Clinical Services Division, International Centre for Diarrhoeal Disease Research, Bangladesh (icddr,b), Dhaka, Bangladesh

${ }^{5}$ Deakin Health Economics, School of Health and Social Development, Deakin University, Melbourne, Victoria, Australia

Acknowledgements The authors would like to ackhowledge icddr,b, Bangladesh Institute of Development Studies, and University of Dhaka for the staff time. icddr,b is grateful to the Governments of Bangladesh, Canada, Sweden and the UK for providing core/unrestricted support.

Contributors NA and MS conceptualised the study. NA, MS and ARS performed the data analysis and interpretation. NA, RA, NS, MS, and ARS contributed to writing. NA, MS and ARS critically reviewed the final version. All authors approved the final version of the manuscript.

Funding The authors received no funding from any funding agency in the public, commercial or not-for-profit sectors.

Competing interests None declared.

Patient consent for publication Not required.

Ethics approval The study analysed a publicly available DHS data set by taking consent from the MEASURE DHS program office.

Provenance and peer review Not commissioned; externally peer reviewed.

Data availability statement Data are available in a public, open access repository. All data relevant to the study are included in the article.

Open access This is an open access article distributed in accordance with the Creative Commons Attribution Non Commercial (CC BY-NC 4.0) license, which permits others to distribute, remix, adapt, build upon this work non-commercially, and license their derivative works on different terms, provided the original work is properly cited, appropriate credit is given, any changes made indicated, and the use is non-commercial. See: http://creativecommons.org/licenses/by-nc/4.0/.

\section{REFERENCES}

1. Abebe SM, Andargie G, Shimeka A, et al. The prevalence of non-communicable diseases in Northwest Ethiopia: survey of Dabat health and demographic surveillance system. BMJ Open 2017;7:e015496-9.

2. Bretzel RG. Comorbidity of diabetes mellitus and hypertension in the clinical setting: a review of prevalence, pathophysiology, and treatment perspectives. Clin Ther 2007;29:S35-S43.

3. Noncommunicable Diseases Progress Monitor 2017. Geneva: World Health organization (who); 2017. Licence: CC BY-NC-SA 3.0 IGO.

4. Danaei G, Finucane MM, Lu Y, et al. National, regional, and global trends in fasting plasma glucose and diabetes prevalence since 1980: systematic analysis of health examination surveys and epidemiological studies with 370 country-years and 2.7 million participants. The Lancet 2011;378:31-40.

5. International Diabetes Federation. IDF diabetes atlas. 6th edn, 2013. 
6. World Health organization (who). global health risks: mortality and burden of disease attributable to selected major risks. Bull World Health Organ 2009;87.

7. Kjeldsen SE. Hypertension and cardiovascular risk: general aspects. Pharmacological Research 2018;129:95-9.

8. Kearney PM, Whelton M, Reynolds K, et al. Global burden of hypertension: analysis of worldwide data. The Lancet 2005;365:217-23.

9. Global status report on noncommunicable diseases 2010. World Health organization 2010;176.

10. World Health Organization (WHO). A global brief on hypertension: silent killer, global public health crisis; World health day 2013 2013:1-40.

11. Lozano R, Naghavi M, Foreman K, et al. Global and regional mortality from 235 causes of death for 20 age groups in 1990 and 2010: a systematic analysis for the global burden of disease study 2010 . The Lancet 2012;380:2095-128.

12. Chowdhury MAB, Uddin MJ, Haque MR, et al. Hypertension among adults in Bangladesh: evidence from a national cross-sectional survey. BMC Cardiovasc Disord 2016;16:1-10.

13. Bala S. Noncommunicable chronic disease in Bangladesh: overview of existing programs and priorities going forward. Rupkatha $J$ Interdiscip Stud Humanit 2013;5:11-21.

14. Abegunde DO, Mathers CD, Adam T, et al. The burden and costs of chronic diseases in low-income and middle-income countries 2015.

15. Directorate General of Health Services. Strategic plan for surveillance and prevention of non-communicable diseases in Bangladesh. Ministry of Health and Family Welfare, 2007.

16. GRM International. Reality Check Bangladesh 2009 - Listening to Poor People's Realities about Primary Healthcare and Primary Education - Year 3. Education 2010.

17. Bleich SN, Koehlmoos TLP, Rashid M, et al. Noncommunicable chronic disease in Bangladesh: overview of existing programs and priorities going forward. Health Policy 2011;100:282-9.

18. Pandey AR, Karki KB, Mehata S, et al. Prevalence and determinants of comorbid diabetes and hypertension in Nepal: evidence from non communicable disease risk factors steps survey Nepal 2013. J Nepal Health Res Counc 2015;13:20-5.

19. Katte J-C, Dzudie A, Sobngwi E, et al. Coincidence of diabetes mellitus and hypertension in a semi-urban Cameroonian population: a cross-sectional study. BMC Public Health 2014;14.

20. Islam A, Biswas T. Chronic non-communicable diseases and the healthcare system in Bangladesh: current status and way forward. Chronic Dis Int 2014;1:1007-2.

21. Mahal A, Karan A, Engelgau M. The economic implications of noncommunicable disease for India. Health, nutrition and population (HNP) discussion paper 2010.

22. Datta BK, Husain MJ, Husain MM, et al. Noncommunicable diseaseattributable medical expenditures, household financial stress and impoverishment in Bangladesh. . SSM - Popul Heal, 2018: 6. 252-8.

23. Sarker AR, Sultana M. Health and economic burden of diabetes in Bangladesh: priorities for attention and control. J Diabetes 2017;9:1118-9.

24. Saquib N, Khanam MA, Saquib J, et al. High prevalence of type 2 diabetes among the urban middle class in Bangladesh. BMC Public Health 2013;13:1032.

25. Joshi $\mathrm{P}$, Islam $\mathrm{S}, \mathrm{Pais} \mathrm{P}$, et al. Risk factors for early myocardia infarction in South Asians compared with individuals in other countries. J Am Med Assoc 2007.

26. Biswas T, Islam A, Rawal LB, et al. Increasing prevalence of diabetes in Bangladesh: a scoping review. Public Health 2016;138:4-11.

27. Rahman M, Zaman MM, Islam JY, et al. Prevalence, treatment patterns, and risk factors of hypertension and pre-hypertension among Bangladeshi adults. J Hum Hypertens 2018;32:334-48.

28. National Institute of Population Research and Training (NIPORT). Bangladesh demographic and health survey 2011. Dhaka, Bangladesh and Calverton, Maryland, USA: NIPORT, Mitra and Associates, and ICF International, 2013.

29. Bangladesh Bureau of Statistics (BBS). Bangladesh Bureau of statistics (BBS). Bangladesh population and housing census 2011. Dhaka, Bangladesh: Bangladesh Bureau of Statistics, Government of the People's Republic of Bangladesh, 2012: 363 p.

30. American Heart Association [Internet]. Available: http://www.heart. org/HEARTORG/

31. World Health Organization (WHO). Definition and diagnosis of diabetes mellitus and intermediate hyperglycemia 2006:1-50.

32. Okosun IS, Chandra KM, Choi S, et al. Hypertension and type 2 diabetes comorbidity in adults in the United States: risk of overall and regional adiposity. Obes Res 2001;9:1-9.

33. Akhter A, Hussain PA, Ali PL. Diabetes Mellitus and Retinopathy in Rural Bangladesh : A Population Based Study 2009.
34. Hu D, Sun L, Fu P, et al. Prevalence and risk factors for type 2 diabetes mellitus in the Chinese adult population: the InterASIA study. Diabetes Res Clin Pract 2009;84:288-95.

35. Rutstein so and KJ. The DHS wealth index. Calverton, Maryland, 2004.

36. Clarke P, Van Ourti T. Calculating the concentration index when income is grouped. J Health Econ 2010;29:151-7.

37. Mauguen A, Begg CB. Using the Lorenz curve to characterize risk Predictiveness and etiologic heterogeneity. Epidemiology 2016;27:531-7.

38. Sun J, Luo H. Evaluation on equality and efficiency of health resources allocation and health services utilization in China. Int $J$ Equity Health 2017;16.

39. Yan K, Jiang Y, Qiu J, et al. The equity of China's emergency medical services from 2010-2014. Int J Equity Health 2017;16:1-8.

40. Omrani-Khoo H, Lotfi F, Safari H. Zargar Balaye Jame S, Moghri J, Shafii M. equity in distribution of health care resources; assessment of need and access, using three practical indicators. Iran J Public Heal 2013;42:1299-308.

41. Zhang T, Xu Y, Ren J, et al. Inequality in the distribution of health resources and health services in China: hospitals versus primary care institutions. Int J Equity Health 2017;16:1-8.

42. WHO. Non-Communicable disease risk factor survey Bangladesh 2010 non-communicable disease risk factor survey. Regional Office for South-East Asia, New Delhi: World Health Organization, 2011.

43. Shihab HM, Meoni LA, Chu AY, et al. Body mass index and risk of incident hypertension over the life course: the Johns Hopkins precursors study. Circulation 2012;126:2983-9.

44. Mayega RW, Makumbi F, Rutebemberwa E, et al. Modifiable SocioBehavioural factors associated with overweight and hypertension among persons aged 35 to 60 years in eastern Uganda. PLoS One 2012;7:e47632.

45. Malekzadeh MM, Etemadi A, Kamangar F, et al. Prevalence, awareness and risk factors of hypertension in a large cohort of Iranian adult population. J Hypertens 2013;31:1364-71.

46. Prevalence CCK. Awareness, treatment, and control of hypertension in rural and urban communities in high-, middle-, and low-income countries. Jama 2013;310.

47. Tibazarwa KB, Damasceno AA. Hypertension in developing countries. Canadian Journal of Cardiology 2014;30:527-33.

48. Gupta R, Deedwania PC, Achari V, et al. Normotension, prehypertension, and hypertension in urban middle-class subjects in India: prevalence, awareness, treatment, and control. Am J Hypertens 2013;26:83-94.

49. Basu S, Millett C. Social epidemiology of hypertension in middleincome countries: determinants of prevalence, diagnosis, treatment, and control in the who SAGE study. Hypertension 2013;62:18-26.

50. van de Vijver SJM, Oti SO, Agyemang C, et al. Prevalence, awareness, treatment and control of hypertension among slum dwellers in Nairobi, Kenya. J Hypertens 2013;31:1018-24.

51. Sarker M, Barua M, Guerra F, et al. Double trouble: prevalence and factors associated with tuberculosis and diabetes comorbidity in Bangladesh. PLoS One 2016;11:e0165396.

52. Tripathy JP, Thakur JS, Jeet G, et al. Prevalence and determinants of comorbid diabetes and hypertension: evidence from non communicable disease risk factor steps survey, India. Diabetes Metab Syndr 2017;11:S459-S465.

53. González K, Fuentes J, Márquez JL. Physical inactivity, sedentary behavior and chronic diseases. Korean J Fam Med 2017;38:111-5.

54. Al-Daghri NM, Al-Attas OS, Alokail MS, et al. Diabetes mellitus type 2 and other chronic non-communicable diseases in the central region, Saudi Arabia (Riyadh cohort 2): a decade of an epidemic. BMC Med 2011;9.

55. Rozanski A, Blumenthal JA, Kaplan J. Impact of psychological factors on the pathogenesis of cardiovascular disease and implications for therapy. Circulation 1999;99:2192-217.

56. Akl C, Akik C, Ghattas H, et al. Gender disparities in midlife hypertension: a review of the evidence on the Arab region. Womens Midlife Health 2017;3.

57. Scavini M, Stidley CA, Shah VO, et al. Prevalence of diabetes is higher among female than male Zuni Indians. Diabetes Care 2003;26:55-60.

58. Ghosh S, Mukhopadhyay S, Barik A. Sex differences in the risk profile of hypertension: a cross-sectional study. BMJ Open 2016;6:e010085-8.

59. Hilawe EH, Yatsuya $H$, Kawaguchi L, et al. Differences by sex in the prevalence of diabetes mellitus, impaired fasting glycaemia and impaired glucose tolerance in sub-Saharan Africa: a systematic review and meta-analysis. Bull World Health Organ 2013;91:671-82.

60. Bureau PR. Noncommunicable diseases among older adults in lowand middle-income countries. Today's Res Aging 2012;11:1-6. 
61. Allen L, Williams J, Townsend N, et al. Socioeconomic status and non-communicable disease behavioural risk factors in low-income and lower-middle-income countries: a systematic review. The Lancet Global Health 2017;5:e277-89.

62. Hu G, Jousilahti P, Barengo NC, et al. Physical activity, cardiovascular risk factors, and mortality among Finnish adults with diabetes. Diabetes Care 2005;28:799-805.

63. Yu T, ter Riet G, Puhan MA, et al. Physical activity and risk of comorbidities in patients with chronic obstructive pulmonary disease: a cohort study. npj Prim Care Resp Med 2017;27:1-5.

64. Association AD. Physical activity / exercise and diabetes. Diabetes Care 2004;26:73-7.

65. Tareque MI, Koshio A, Tiedt AD, et al. Are the rates of hypertension and diabetes higher in people from lower socioeconomic status in Bangladesh? results from a nationally representative survey. PLoS One 2015;10:e0127954-17.

66. Akter S, Rahman MM, Abe SK, et al. Prevalence of diabetes and prediabetes and their risk factors among Bangladeshi adults: a nationwide survey. Bull World Health Organ 2014;92:204-13.

67. Rasheed S, Jahan S, Sharmin T, et al. How much salt do adults consume in climate vulnerable coastal Bangladesh? BMC Public Health 2014;14:1-7.

68. Bangladesh Bureau of Statistics. Ministry of Planning. Report of the Household Income \& Expenditure (HIES) 20102011.
69. Chowdhury MAB, Adnan MM, Hassan MZ, Trends HZ. Trends, prevalence and risk factors of overweight and obesity among women of reproductive age in Bangladesh: a pooled analysis of five national cross-sectional surveys. BMJ Open 2018;8:e018468-12.

70. Kolterman OG, Insel J, Saekow M, et al. Mechanisms of insulin resistance in human obesity: evidence for receptor and postreceptor defects. J. Clin. Invest. 1980;65:1272-84.

71. Haffner SM, Valdez RA, Hazuda HP, et al. Prospective analysis of the insulin-resistance syndrome (syndrome X). Diabetes 1992;41:715-22.

72. Khaodhiar L, McCowen KC, Blackburn GL. Obesity and its comorbid conditions. Clin Cornerstone 1999;2:17-31.

73. Sowers JR. Obesity and cardiovascular disease. Clin Chem 1998;44:1821-5.

74. Datta BK, Husain MJ, Husain MM, et al. Noncommunicable diseaseattributable medical expenditures, household financial stress and impoverishment in Bangladesh. SSM Popul Health 2018;6:252-8.

75. Kien VD. Inequalities in non-communicable diseases in urban Hanoi, Vietnam: health care utilization, expenditure, and responsiveness of commune health stations 2016.

76. Jaspers L, Colpani V, Chaker L, et al. The global impact of noncommunicable diseases on households and impoverishment: a systematic review. Eur J Epidemiol 2015;30:163-88.

77. Wagstaff $A$, van DE. Paying for health care : quantifying fairness, catastrophe, and impoverishment, with applications to Vietnam, 1993-98 2015;56. 